purpose of crushing an oxalate of lime calculus, the character of which is generally recognised by its sharp ringing sound. The fragments are always sharp and irritating to the bladder, and it not uncommonly happens that the lithotrite fails to act on the great mass of the stone.

Most calculi are conaposed of uric acid. We have a collection of above 200 , and of these there are of uric acid alone, 30 ; of urate of ammonia, 13 ; of calculi composed of two layers, uric acid nucleus, 16 ; urate of ammonia nucleus, 25 ; of calculi composed of three layers, uric acid nucleus, 7 ; urate of ammonia, 18: total, 111. But this number would be much higher were it not that very many uric acid and urate of ammonia calculi have been thrown away as too small and too common for preservation. Next in frequency comes the oxalate of lime calculus, amounting to 40 ; of the fusible calculus, 19 ; phosphate of lime, 11 ; cystic oxide, 2. The other specimens are composed of carbonate of lime, or are concretions formed upon foreign bodies.

ON THE

\section{ACTION OF TINCTURE OF PERCHLORIDE OF IRON IN THE CURE OF RENAL AND URINARY AFFECTIONS.}

Bx ARTHUR HILL HASSALL, M.D. LoND. SENIOR PHXSICIAN TO THE ROYAL FBER HOSPITAL.

Thene are few remedies more frequently prescribed in the treatment of renal and urinary affections than is the tincture of perchloride of iron, formerly called muriated tincture of iron. The value of that remedy in a variety of such cases is undoubted, as in the albuminuria of Bright's disease, in hæmorrhage from the kidney, bladder, or urethra, in spasmodic stricture, \&c.

The tincture of the perchloride of iron consists of two atoms of iron in combination with three of chlorine, dissolved in water to which rectified spirit has been added; and it possesses the properties of an astringent, tonic, and styptic, coagulating blood or albumen with which it is brought into contact, and constringing the vessels and tissues to which it is applied.

Now, this astringent property is just that which a remedy ought to possess to be useful in the cases above referred to, and by it, it is usually supposed, it exerts its beneficial action; and certainly nothing would appear to be more plausible and more natural than this explanation.

Having, after the administration of this remedy, repeatedly tested the urine for the purpose of detecting in it the presence of iron, and having failed to discover the faintest trace of the metal, I was led to doubt the correctness of this view, and was induced to institute some experiments, in order to put the matter to the proof.

To a patient, T. L_—, labouring under an habitual urinary discharge, I administered for the period of more than a week a drachm of the tincture thrice daily; but, although I tested the urine on several occasions, in no instance could $i$ detect the smallest trace of iron, notwithstanding that a pint of the urine was evaporated to a small bulk before being examined.

To a patient now in the Royal Free Hospital, Charles Swho is suffering from an extravasation of blood, three drachms of the tincture were administered on two consecutive days. The whole of the urine passed in the twenty-four hours of each day was collected, a pint of each sample evaporated to a small bulk, and tested as before, but with a similar negative result.

Lastly, I myself took in the course of a day three drachms of the tincture; the urine passed in the twenty-four hours being collected and analyzed, not only on the day on which the medicine was taken, but on the preceding and succeeding days. Still no iron was found.

I could enumerate several other instances in which iron had been taken and the urine analyzed without even traces of the metal being subsequently discovered. The examples, however, I have quoted are sufficient to show that the tincture of perchloride of iron does not produce its beneficial effects, as generally supposed, in restraining the amount of albumen or of blood discharged from the kidney or other portion of the genitourinary mucous track by coming in contact with the seat of the lesion and by its action as an astringent.

How, then, does this remedy act? That much of the iron contained in the sesquichloride does not find its way into the circulation at all, but escapes from the system with the undigested portions of the food, is certain ; the black discoloration of the fres under the use of this tincture, and indeed, I believe, under all the preparations of iron, is well known, the colour being due to a combination of the iron with a portion of the sulphur of the food-sulphuret of iron being thus formed. It might therefore be very plausibly presumed that while the greater part of the iron is thus thrown off by the bowels without having been absorbed at all, the hydrochloric acid being set free, enters the circulation, is eliminated by the kidneys, and so comes in contact with the seat of lesion; and that it is to the acid, and not to the iron, that the benetit is to be attributed. But if this view be correct, it is capable of being substantiated by experiment; and with this object I administered to two persons drachm doses, repeated thrice daily, of the perchloride; the urine of the twenty.four hours being collected and analyzed before, during, and after the administra. tion of the ferruginous preparation. The results will be seen in the following tables:-

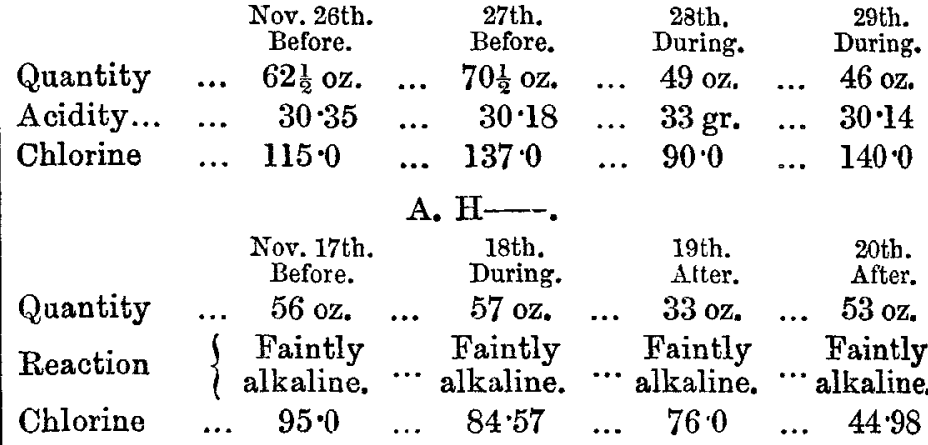

The above figures show, lst, that there was no increase in the acidity of the urine consequent upon taking the remedy; 2nd, that there was no increase of chlorine, and that therefore the hydruchloric acid of the perchloride was not eliminated by the kidneys either in the free or combined state : thus proving that the second view mentioned of the action of the remedy is also entirely unfounded.

These results are not a little remarkable; and we have, therefore, still to inquire, in what way does this medicine act in the cure of disease? Its effects are too rapid to allow it to be supposed that its operation is due to its influence in improving the condition of the blood by its action on the red corpuseles. We appear, therefore, driven to the conclusion that the perchloride of iron acts by its stimulating influence on the nervous system.

These observations are interesting, not alone as concerns this one preparation of iron; they also probably apply more or less to most of the other medicinal preparations of that metal, since it is at least certain that by far the greater part of the iron contained in them is not absorbed but escapes from the system by the bowels like that of the perchloride.

The particulars herein recorded are suggestive of further experiments calculated to throw additional light upon the subject, and which hereafter I may have the opportunity of instituting.

Wimpole-street, Dec. 1864.

\section{REMARKABLE CASE OF PISTOL-WOUND OF HAND.}

By JAMES SAVAGE, M.R.C.S., Undergrad. Lond.

E. G- aged twelve years, was brought to my surgery on the morning of the 6th of August, about seven o'clock, by his mother, who told me that he had been frightening birds from the corn, and that with a pistol which he used for that purpose he had blown off part of his hand. The charge consisted of powder and paper. Upon examination I found the index finger and head of the metacarpal bone of the left hand com. pletely smashed, with the muscles and skin a good deal torn, but no further injury to surrounding parts. He had had his breakfast, and soon after entering my house he vomited it up. I inquired if he had good health, and was told "yes," but that occasionally he was troubled with worms. I examined his heart, and finding its action regular and tolerably strong at once gave him chloroform, and, having pared off the jagged parts, I cut across the metacarpal bone with the forceps about its centre. There was no bleeding, and so no ligature was used. 
The edges came easily together, and were kept so by four sutures. Water-dressing was applied and ordered to be continued. He rallied at once from the chloroform (of which he had about two drachms on a silk handkerchief), and, having had a drink of cold water, walked firmly away home, a distance of nearly half a mile, with his arm in a sling. He experienced little or no pain during the remainder of the day, and passed a good night.

Aug. 7th.-Dressings not removed, wound looking well.

8th. - Had a good night; wound dressed with cold water and looking very well. He began to experience slight pain in shoulders, arms, and legs; these pains got worse, and on the night of the 12th I was sent for and found my patient in fearful suffering. I carefully examined the wound; it was looking heal thy and healing rapidly. There was no pain in the injured hand, but he was racked in both shoulders, legs, and arms, particularly the right side. I ordered some hot fomentations and a grain of solid opium every three hours. Next morning, though the remedies had afforded temporary relief, in reality he was no better; and, thinking there might be some intestinal irritation, I gave him a calomel and jalap powder, which purged him freely; but he passed no worms, neither did he after a black draught, which was administered a few hours afterwards. His pains continued unabated, in fact they got worse, and he could neither eat, drink, nor sleep. He described them as being similar to knives running into him. His bowels and kidneys acted regularly, and the wound healed up soundly. There was still no pain whatever in the injured hand or forearm, but elsewhere it was excruciating, and his cries were so loud and distressing that many a passer-by has gone to the house and asked the cause. Upon more closely questioning his parents I now discovered that a week before his accident he had fallen from a tree on to his right shoulder, a distance of about twelve feet, that for several minutes he was unable to get up, and that ever since he could make very little use of his right hand or arm. I now examined this part and could find nothing wrong beyond a good deal of soreness, which was general all over his limbs. He experienced no particular pain when I rotated or otherwise moved the shoulder-joint. I ordered poppy fomentations to right shoulder and arm; to continue opium and to take ten grains of cinchonine in an ounce of port wine every three hours. He was somewhat relieved for a few days, but not materially, and Mr. Cass, of Goole, was called in to see him with me. We agreed to give him fifteen grains of carbonate of iron every four hours, ordered the injured hand to be steeped in hot water, the morphia to be coninued, and strong turpentine cloths to be applied to the whole length of the spine, $\mathrm{Mr}$ Cass saw him four or five times with me at intervals of two or three days, but our patient was no better, and I was acain left in sole charge. The wound had opened and was beginning to suppurate. Bread poultices were applied to it. His agony was terrible, the pain chiefly in the shoulders and thighs. Whenever the effect of the morphia (I had ordered it lately on account of the constipating effect of the opium) was gone, he cried out piteously. I carefully looked into the wound for the cause, and examined the stimp of the metacarpal bone. I conld see nothing, nor was it tender when touched. His symptoms continued, with little variation, the same for about two months, during which time every likely remedy which I could think or hear of was tried without effect : bella. donna, aconite, chloroform; the spine was blistered; morphia was injected subcutaneously, and other things-all to no purpose. One morning, however, I went and found him quite without pain ; it left him suddenly about one $A M_{\text {. }}$, and he felt no more of it all day till night, when it returned, though not co aeverely. This was the first remission. He was worn nearly to a skeleton. I ordered him as much new milk and port wine as he could take, and increased the cinchonine to a scruple every four hours. His pain now only lasted two or three hours at a time, and in this way gradually left him, so that in a fortnight he was perfectly free from it. His appetite soon returned, and he quickly recovered. He is now running about. The wound has not quite, though very nearly, healed. I consider this a most singular case, and I have only three remarks to make on it :-

1st. Was all this disturbance the result of the fall or the pistol-wound, or the combination of the two?

2nd. Was it merely the shock to the system generally, or was it injury to some particular nerve or set of nerves?

3rd. Did any of the remedies benefit him, and if so, which one?

I could write many more details concerning this interesting case, but am afraid of occupying too much space.

Swinefleet, Goole, Dec. 1864 .

\section{Aflirror}

OF THE PRACTICE OF

\section{MEDICINE AND SURGERY IN THE}

HOSPITALS OF LONDON.

Nulla autem est alia pro certo noscendi via, nisi quamplurimas et morborum et dissectionum historias, tum aliorum, tum proprias collectas habere, et inter

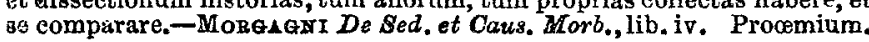

\section{ST. GEORGE'S HOSPITAL.}

TUBERCULOUS MASSES, THE SIZE OF HAZEL-NUTS, IN EACH HEMISPHERE OF THE BRAIN; CONVILLIONS; FATAL RESULT.

(Under the care of Dr. Pinvas.)

THE occurrence of tubercle in the brain in the adult is a circumstance of interest from its infrequency as contrasted with the same affection in childhood; but in either case it seldom exists without the presence of the same deposit in other organs. The number and size of the tuberculous deposits in the brain vary considerably : when large, they are few, but rarely so few as in the following case, wherein a single mass, the size of a hazel-nut, occupied the right and left cerebrum respectively. The anomalous symptoms present during life, with the convulsive attacks, are fully explained by the details of the post-mortem inspection; and, in all probability, the cerebral invasion may have been induced by the fall related in the patient's history.

Charles $\mathrm{D} \longrightarrow$, aged forty-nine, was admitted on the 21st of September last. He was dark.haired, and fairly nourished; and complained on admission of a number of vague symptoms, of which diarrhœa was the most definite. He had had several fits, described as of an epileptic character, and supposed to be due to a fall he had in the spring of the year. In manner he was dull and stupid, and nothing could be made of him. The skin and tongue were natural; the pulse weak, not frequent. $\mathrm{He}$ was given sulphuric acid, with Battley's sedative solution, in logwood decoction, and broth diet. The patient got up on most days for a few hours, but continued to complain of feeling "ill all over." The motions were scanty, slimy, and offensive, and he was getting weaker. On the morning of the 27 th he had an epileptic fit (the last, it was ascertained, had occurred but a few days previous to admission). When seen at one o'clock P.M., the limbs were much convulsed, and he was wholly unconscious, the pulse, which was small, beating 140 . He had a succession of such seizures at very short intervals, and no return of consciousness. At midnight he died. The treatment at first adopted was continued throughout. He was given for diet broth, and afterwards milk and beef-tea. On the 28 th an ordinary diet was ordered. He took very little of anything.

A utopsy, thirteen hours after death - There was nothing unusual in the condition of the body. The arachnoin was generally opaque, and under it was a good deal of clear fluid. There was also a quantity of clear fluid in the arachnoid cavity, for several ounces remained in the base of the skull when the brain had been taken out. The lateral ventricles contained about an ounce of clear fluid. There was a crude tubercle, the size of a hazel-nut, in each hemisphere of the cerebrum sitnated at the upper part, and so imbedded that the most superficial parts of the tubercle were in contact with the pia mater. In the left hemisphere the tubercle was in the middle; in the right it was in the posterior lobe. There were no other tubercles in the encephalon. Both lungs contained abundance of miliary and crude tubercles; at the apex of the right were a few small vomicæ. The heart was natural. The liver was cirrhosed, the surface granular, and, on section, the tissue was seen divided into small globuies. The kidneys and other viscera were natural. 